\title{
CO Adsorption-Driven Surface Segregation of Pd on Au/Pd Bimetallic Surfaces: Role of Defects and Effect on CO Oxidation
}

\author{
Hyun You Kim ${ }^{\dagger} *$ and Graeme Henkelman* \\ Department of Chemistry, University of Texas at Austin, Austin, Texas 78712-0165, United States
}

Supporting Information

ABSTRACT: We use density functional theory (DFT) to study CO-adsorption-induced Pd surface segregation in $\mathrm{Au} / \mathrm{Pd}$ bimetallic surfaces, dynamics of $\mathrm{Pd}-\mathrm{Au}$ swapping, effect of defects on the swapping rate, CO-induced Pd clustering, and the reaction mechanism of $\mathrm{CO}$ oxidation. The strong $\mathrm{CO}$ philic nature of $\mathrm{Pd}$ atoms supplies a driving force for the preferential surface segregation of $\mathrm{Pd}$ atoms and $\mathrm{Pd}$ cluster formation. Surface vacancies are found to dramatically accelerate the rate of $\mathrm{Pd}-\mathrm{Au}$ swapping. We find that $\mathrm{Pd}$

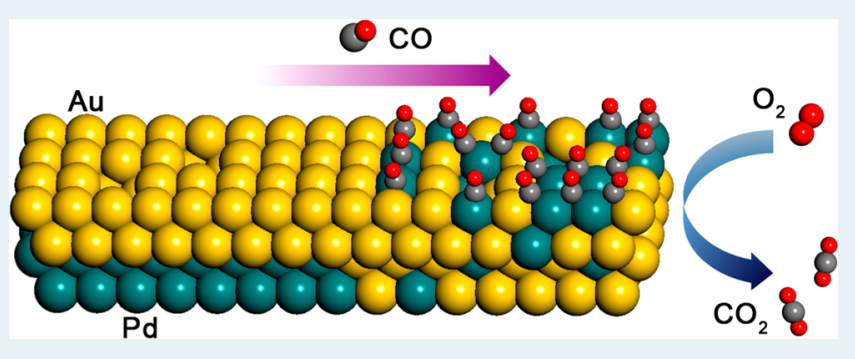
clusters consisting of at least four Pd atoms prefer to bind $\mathrm{O}_{2}$ rather than $\mathrm{CO}$. These clusters facilitate the rapid dissociation of $\mathrm{O}_{2}$ and supply reactive oxygen species for $\mathrm{CO}$ oxidation. Our findings suggest that geometric, electronic, and dynamic effects should be considered in the function of bimetallic alloys or nanoparticles whose components asymmetrically interact with reacting molecules.

KEYWORDS: density functional theory, gold, palladium, heterogeneous catalysis, adsorption-induced segregation, CO oxidation

\section{INTRODUCTION}

The catalytic activity of bimetallic alloys or nanoparticles (NPs) can be optimized by controlling structural factors, such as the alloying element and concentration. ${ }^{1,2}$ The ensemble (geometric) and ligand (electronic) effects have been shown to systematically alter the catalytic activity of bimetallic catalysts. 3,4

Computational methods such as density functional theory (DFT) can effectively aid the design of bimetallic catalysts at the atomic scale. ${ }^{5-10}$ Computational approaches generally assume that the thermodynamically most favorable structure of clean bimetallic catalysts is stable. Experiments, however, question the generality of this assumption. Somorjai and coworkers reported that the core and shell elements of Pd (core) $@ \mathrm{Rh}$ (shell) NP are reversible under ambient reaction conditions. $^{11,12}$ Using ambient-pressure X-ray photoelectron spectroscopy, they showed that as the Pd@Rh NPs supported on oxidized silicon wafer oxidize $\mathrm{CO}$ with $\mathrm{NO}(2 \mathrm{CO}+2 \mathrm{NO} \rightarrow$ $2 \mathrm{CO}_{2}+\mathrm{N}_{2}$ ), Pd is enriched in the surface layers, leading to a structural rearrangement to the $\mathrm{Rh} @ \mathrm{Pd}$ reverse core-shell geometry. The original $\mathrm{Pd} @ \mathrm{Rh}$ core-shell structure was recovered when $\mathrm{CO}$ was removed from the gas phase. Chen and co-workers reported such a $\mathrm{CO}$-induced $\mathrm{Pt}$ segregation in $\mathrm{TiO}_{2}$-supported $\mathrm{Pt}-\mathrm{Au} \mathrm{NPs}$, as well. ${ }^{13}$

In the case of bimetallic surfaces, the Goodman group reported that $\mathrm{Pd}$ segregated to the surface layer as $\mathrm{Au}$ overlayered-Pd(100) bimetallic alloys were exposed to $\mathrm{CO}$ oxidation conditions. ${ }^{14,15}$ More Pd was segregated in the surface layer as the $\mathrm{CO}$ partial pressure was increased. The surface segregated $\mathrm{Pd}$ atoms were found to catalyze $\mathrm{CO}$ oxidation, and the authors suggested that contiguous $\mathrm{Pd}$ atoms in the surface layer provided the catalytically active site. Their rationale was that contiguous $\mathrm{Pd}$ atoms bind and dissociate the $\mathrm{O}_{2}$ molecule supplying $\mathrm{O}$ atoms for $\mathrm{CO}$ oxidation.

Since adsorption- or reaction-induced surface segregation of a specific element in bimetallic alloys and NPs affects their chemical properties, information on the reaction- or adsorption-induced surface segregation is important for catalyst design.

Interatomic swapping of core and shell elements reported in Pd- or Pt-based bimetallic catalysts is presumably driven by an asymmetrically strong $\mathrm{CO}$ adsorption on Pd or Pt atoms. ${ }^{13-16}$ DFT results presented by Soto-Verdugo and Metiu showed that $\mathrm{CO}$ prefers to bind on $\mathrm{Pd}$ rather than on $\mathrm{Au}$ in $\mathrm{Au} / \mathrm{Pd}$ bimetallic alloys. ${ }^{16}$ The same trend was reported for Pt/Au NPs by Chen and co-workers. ${ }^{13}$ Although several previous reports on the CO-induced preferential surface segregation suggested that the strong $\mathrm{CO}$ binding on $\mathrm{Pd}$ or Pt induces the atomic swapping, detailed information on the swapping process is still sketchy.

Here, we demonstrate the dynamics of the CO-adsorptiondriven $\mathrm{Pd}-\mathrm{Au}$ swapping, $\mathrm{Pd}$ surface segregation, that occurs in the $\mathrm{Pd}-\mathrm{Au}(111)$ and $\mathrm{Pd}-\mathrm{Au}(100)$ bimetallic alloys. We found that the relatively strong $\mathrm{CO}$ binding on $\mathrm{Pd}$, as compared with that on $\mathrm{Au}$, stabilizes the $\mathrm{Pd}-\mathrm{CO}^{*}$ in the surface layer and supplies a driving force for Pd surface segregation. Surface $\mathrm{Au}$ vacancies accelerate the $\mathrm{Pd}-\mathrm{Au}$ swapping, highlighting the essential role of defects on the swapping dynamics. The

Received: July 30, 2013

Revised: September 26, 2013 


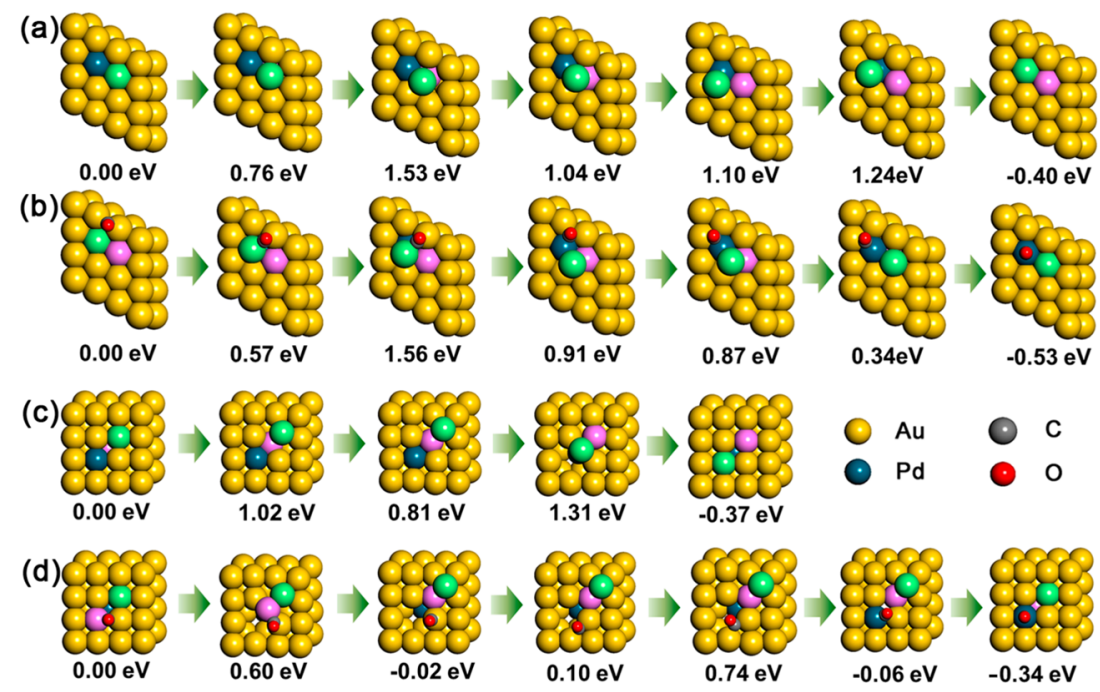

Figure 1. $\mathrm{Pd}-\mathrm{Au}$ swapping process and relative energy of swapping intermediates in clean $\mathrm{Pd}-\mathrm{Au}$ surfaces: $(\mathrm{a}) \mathrm{Pd}-\mathrm{Au}(111),(\mathrm{b}) \mathrm{Pd}-\mathrm{Au}(111)-$ $\mathrm{CO},(\mathrm{c}) \mathrm{Pd}-\mathrm{Au}(100)$, and (d) $\mathrm{Pd}-\mathrm{Au}(100)-\mathrm{CO}$. The relative energy of the intermediates was calculated relative to the unstable position of the Pd atom. The $\mathrm{Pd}-\mathrm{Au}$ swapping proceeds from left to right, stabilizing the system. Au atoms involved in the swapping process are colored in light green and pink.

morphology of reactive species and the role of the $\mathrm{Pd}$ concentration on the $\mathrm{CO}$ oxidation mechanism are discussed.

\section{COMPUTATIONAL METHOD}

We performed spin-polarized DFT calculations in a plane-wave basis with the VASP code $^{17}$ and the PBE GGA functional. ${ }^{18}$ Valence electrons were described by plane waves up to an energy cutoff of $290 \mathrm{eV}$, and the core electrons were described within the projector augmented wave framework. ${ }^{19}$ To study the $\mathrm{Pd}-\mathrm{Au}$ swapping mechanism, $4 \times 4 \mathrm{Au}(111)$ and $\mathrm{Au}(100)$ slabs with four atomic layers and $20 \AA$ of vacuum thickness were constructed. A single subsurface $\mathrm{Au}$ atom was substituted with a Pd atom to give an in-plane Pd concentration of $1 / 16=$ $6.25 \%$. The top two surface layers were relaxed during geometric optimization. We used a $2 \times 2 \times 1$ k-points grid sampling of the Brillouin zone for all calculations. Sensitivity tests show that our results are robust with respect to the calculation and model parameters, including the choice of oxygen pseudopotential, k-point grid, cutoff energy, and size and thickness of the slab (see Supporting Information Table S1 for details). The energy of $\mathrm{CO}$ adsorption on the $\mathrm{Pd}-\mathrm{Au}(100)$ calculated with a harder oxygen pseudopotential and an energy cutoff of $500 \mathrm{eV}$ was changed by only $0.07 \mathrm{eV}$.

Final convergence criteria for the electronic wave function and geometry were $10^{-4} \mathrm{eV}$ and $0.01 \mathrm{eV} / \AA$, respectively. We used the Gaussian smearing method with a width of $0.2 \mathrm{eV}$ to improve convergence with respect to states near the Fermi level. The location and energy of transition states (TSs) were calculated with the climbing-image nudged elastic band method $^{20,21}$

\section{RESULTS AND DISCUSSION}

3-1. Energetics of Pd-Au Swapping in Clean Surfaces. In vacuum, a Au-covered $\mathrm{Pd}$ overlayer is the thermodynamically most stable configuration of the $\mathrm{Au} / \mathrm{Pd}$ bimetallic alloy. ${ }^{22}$ Figure 1a, c and Table 1 present the process of $\mathrm{Pd}-\mathrm{Au}$ swapping in both clean $\mathrm{Pd}-\mathrm{Au}(111)$ and $\mathrm{Pd}-\mathrm{Au}(100)$ surfaces, the driving force and the activation energy barrier $\left(E_{\mathrm{b}}\right)$, and the approximate rate of swapping is calculated at 300
Table 1. Pd-Au Swapping Energy Barrier $\left(E_{\mathrm{b}}\right)$ and the Approximate Rate of Pd-Au Swapping Calculated at $300 \mathrm{~K}$ with Harmonic-Transition State Theory, Assuming a Standard Prefactor of $\nu=10^{12} \mathrm{~s}^{-1 a}$

\begin{tabular}{|c|c|c|c|c|}
\hline & $\mathrm{Pd}-\mathrm{Au}(111)$ & $\underset{\mathrm{Ad}-}{\mathrm{Pd}-}$ & $\begin{array}{c}\mathrm{Pd}-\mathrm{Au}(111)- \\
\mathrm{Vac}\end{array}$ & $\begin{array}{c}\mathrm{Pd}-\mathrm{Au}(111) \\
\mathrm{Vac}-\mathrm{CO}\end{array}$ \\
\hline \multirow{3}{*}{$\begin{array}{l}E_{\mathrm{b}}(\mathrm{eV}) \\
\text { rate } \\
\left(\mathrm{s}^{-1}\right)\end{array}$} & 1.53 & 1.56 & 0.73 & 0.81 \\
\hline & $1.98 \times 10^{-14}$ & $6.21 \times 10^{-15}$ & $5.45 \times 10^{-1}$ & $2.47 \times 10^{-2}$ \\
\hline & $\mathrm{Pd}-\mathrm{Au}(100)$ & $\begin{array}{c}\mathrm{Pd}- \\
\mathrm{Au}(100)- \\
\mathrm{CO}\end{array}$ & $\frac{\mathrm{Pd}-}{\mathrm{Au}(100)-\mathrm{Vac}}$ & $\begin{array}{c}\mathrm{Pd}-\mathrm{Au}(100)- \\
\mathrm{Vac}-\mathrm{CO}\end{array}$ \\
\hline$E_{\mathrm{b}}(\mathrm{eV})$ & 1.31 & 0.76 & 0.42 & 0.51 \\
\hline $\begin{array}{l}\text { rate } \\
\qquad\left(\mathrm{s}^{-1}\right)\end{array}$ & $9.84 \times 10^{-11}$ & $1.71 \times 10^{-1}$ & $8.80 \times 10^{4}$ & $2.71 \times 10^{3}$ \\
\hline
\end{tabular}

${ }^{a} E_{\mathrm{b}}$ and the rate of $\mathrm{Pd}-\mathrm{Au}$ swapping were calculated to the direction that lowers the energy of the system.

$\mathrm{K}$ with harmonic-transition state theory, assuming a standard prefactor of $\nu=10^{12} \mathrm{~s}^{-1}$. A Pd atom thermodynamically prefers the subsurface layer, as compared with the surface layer. The $\mathrm{Pd}-\mathrm{Au}$ swapping process, the barrier, and the rate have been calculated in the direction where the $\mathrm{Pd}-\mathrm{Au}$ swapping stabilizes the system, swapping a surface Pd atom with a subsurface $\mathrm{Au}$ atom.

In both cases, an adjacent surface $\mathrm{Au}$ atom to the $\mathrm{Pd}$ atom moves onto the surface to become an adatom, to make space (a vacancy) for the $\mathrm{Pd}-\mathrm{Au}$ swapping process. Adatom/vacancy formation is a high-energy process, and the energy barrier for $\mathrm{Pd}-\mathrm{Au}$ swapping is also (comparably) high. The swapping barrier of the more open $\mathrm{Pd}-\mathrm{Au}(100)$ surface is only somewhat lower than that of the close packed $\mathrm{Pd}-\mathrm{Au}(111)$ ( 1.31 and $1.53 \mathrm{eV}$, respectively, as listed in Table 1). The low calculated rates confirm that, in the case of clean surfaces, Pd atoms would be pinned to their original positions at low temperature; even the Pd subsurface segregation is thermodynamically favorable (Table 1 ). Measurable swapping rates of 10 $\mathrm{s}^{-1}$ are achievable at $650 \mathrm{~K}$ for $\mathrm{Pd}-\mathrm{Au}(111)$ and $470 \mathrm{~K}$ in $\mathrm{Pd}-$ $\mathrm{Au}(100)$, respectively. 
We found that two Pd atoms in the surface layer repel and favor being separated from each other. The formation energy of a $\mathrm{Pd}-\mathrm{Pd}$ dimer from two separated $\mathrm{Pd}$ atoms is $0.1 \mathrm{eV}$, meaning that $\mathrm{Pd}$ cluster formation is unfavorable. Configurational entropy would additionally destabilize the $\mathrm{Pd}-\mathrm{Pd}$ dimer at low Pd surface concentrations. The swapping barrier of the second Pd atom in the presence of a preswapped Pd atom in the surface layer would be higher than the barrier of the first swapping.

On the other hand, strong $\mathrm{CO}$ binding to Pd stabilizes the $\mathrm{Pd}-\mathrm{CO}^{*}$ complex in the surface layer and supplies a driving force for the Pd surface segregation. (Figure $1 b, d$ and Table 1). CO lowers the $E_{\mathrm{b}}$ of Pd surface segregation, especially in the case of $\mathrm{Pd}-\mathrm{Au}(100)$. Presumably, relatively stronger $\mathrm{CO}$ binding on the $\mathrm{Au}(100)$ surface $(-0.63 \mathrm{eV}, \mathrm{Au}-\mathrm{Au}$ bridge position) than the $\mathrm{Au}(111)$ surface $(-0.25 \mathrm{eV}, 3$-fold hollow position) lowers the energy of swapping intermediates in the $\mathrm{Pd}-\mathrm{Au}(100)-\mathrm{CO}$ complex. However, the $\mathrm{Pd}-\mathrm{Au}$ swapping still requires an adatom formation in both cases, so the $E_{\mathrm{b}}$ is still high (Table 1). Although $\mathrm{CO}$ exchanges the stable location of $\mathrm{Pd}$, the $\mathrm{Pd}-\mathrm{Au}$ swapping is a rare event, even in the presence of CO.

3-2. Energetics of $\mathrm{Pd}-\mathrm{Au}$ Swapping in Defected Surfaces. In their polarization-modulation infrared reflection adsorption spectroscopy (PM-IRRAS) study on the wellannealed and freshly ion-sputtered Au-overlayered $\operatorname{Pd}(100)$, Goodman and co-workers reported that CO-induced $\mathrm{Pd}$ surface segregation is more prominent in the freshly ionsputtered $\mathrm{Au} / \mathrm{Pd}(100)$ surface. ${ }^{15}$ Contiguous $\mathrm{Pd}$ atoms, a result of high Pd surface concentration, were observed in the freshly sputtered specimen, even when it was exposed to very low $\mathrm{CO}$ partial pressure $\left(1 \times 10^{-6}\right.$ Torr $)$. On the other hand, higher $\mathrm{CO}$ partial pressure is required for the formation of contiguous $\mathrm{Pd}$ atoms in the well-annealed specimen. ${ }^{15}$ This finding suggests a critical effect of surface roughness or defects for the dynamics of the $\mathrm{Pd}-\mathrm{Au}$ swapping. Moreover, recent experimental findings on the structure of $\mathrm{Au} / \mathrm{Pd}$ bimetallic NPs confirm the presence of surface vacancies in small NPs, as well. ${ }^{23,24}$ HRTEM studies by $\mathrm{Xu}$ et al. showed that vacancies appear in the surface layer of $\mathrm{Pd}-\mathrm{Au} \mathrm{NPs}^{24}$ Meija-Rosales et al. experimentally observed surface vacancies in $\mathrm{Au}-\mathrm{Pd}$ NPs and confirmed the structure by molecular dynamics simulations. ${ }^{23}$ These findings suggest the consideration of a defect on the PdAu swapping processes by introducing a Au surface vacancy.

Figure $2 \mathrm{a}$, c shows that a Au vacancy facilitates the $\mathrm{Pd}-\mathrm{Au}$ swapping pathway without adatom formation or surface distortion. A Au vacancy in the surface layer of the Pd$\mathrm{Au}(111)-\mathrm{Vac}$ and $\mathrm{Pd}-\mathrm{Au}(100)-\mathrm{Vac}$, therefore, lowers the swapping energy barriers (Table 1). Pd penetration from the surface layer to the subsurface layer is the rate-determining step due to the relatively low energy of the intermediate structure: the $\mathrm{Au} / \mathrm{Pd}$ surface with a subsurface $\mathrm{Au}$ vacancy.

Figure $2 \mathrm{~b}, \mathrm{~d}$ shows that the preferential $\mathrm{CO}$ adsorption on $\mathrm{Pd}$ again stabilizes the $\mathrm{Pd}-\mathrm{CO}^{*}$ complex in the surface of the defected $\mathrm{Pd}-\mathrm{Au}(111)-\mathrm{Vac}-\mathrm{CO}$ and $\mathrm{Pd}-\mathrm{Au}(100)-\mathrm{Vac}-\mathrm{CO}$, leading to surface segregation of $\mathrm{Pd}$. The presence of $\mathrm{CO}$ again supplies a driving force for Pd surface segregation but does not accelerate the Pd-Au swapping (Table 1).

In the case of the $\mathrm{Pd}-\mathrm{Au}(111)-\mathrm{Vac}$ systems (Figure 2a, b) DFT predicts a structure with a subsurface Au vacancy and a Pd in the surface layer as a more stable structure than the final state with a surface vacancy. A similar result was acquired for the clean $\mathrm{Au}(111)$ surface, as well; the result is insensitive to the

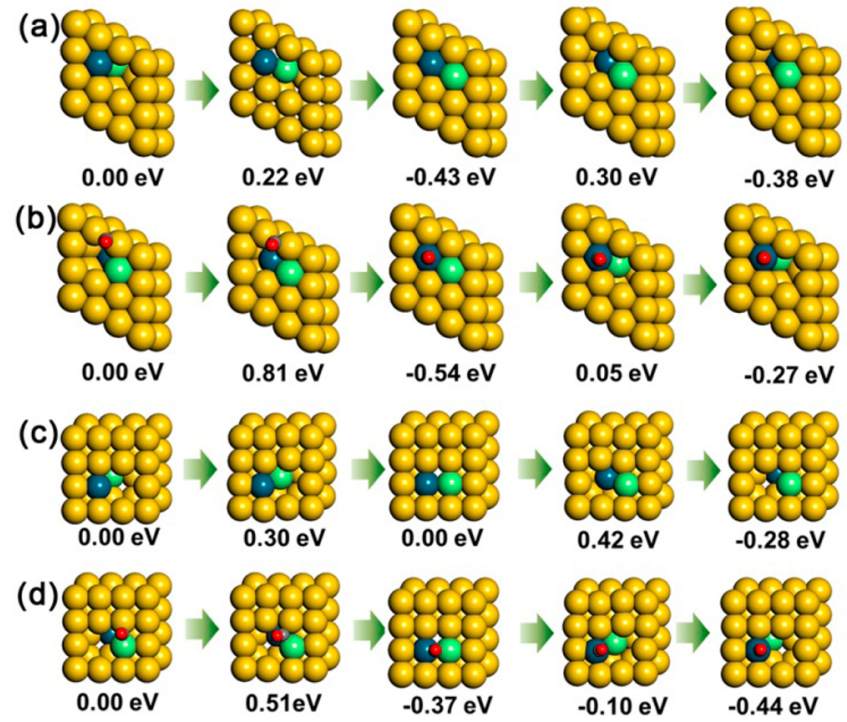

Figure 2. $\mathrm{Pd}-\mathrm{Au}$ swapping process and relative energy of swapping intermediates in defected Pd-Au surfaces: (a) Pd-Au(111)-Vac, (b) $\mathrm{Pd}-\mathrm{Au}(111)-\mathrm{Vac}-\mathrm{CO}$, (c) Pd-Au(100)-Vac, and (d) Pd-Au(100)Vac-CO. Relative energy of intermediates was calculated relative to the unstable position of the $\mathrm{Pd}$ atom. The $\mathrm{Pd}-\mathrm{Au}$ swapping proceeds from left to right, stabilizing the system. A Au atom involved in the swapping process is colored in light green.

calculation parameters, including k-points grid, energy cutoff, and slab thickness. This is a somewhat surprising result because the subsurface vacancy generates more dangling bonds than the surface oxygen vacancy. However, because the formation of the surface $\mathrm{Pd}-\mathrm{CO}^{*}$ is insensitive to the location of the $\mathrm{Au}$ vacancy, the main conclusions reached here are not affected.

Our findings confirm that, under $\mathrm{CO}$ oxidation conditions, $\mathrm{CO}$ supplies a driving force for the preferential surface segregation of $\mathrm{CO}$-philic $\mathrm{Pd}$ atoms in the $\mathrm{Au} / \mathrm{Pd}$ bimetallic alloys so that the local geometry of the $\mathrm{Au} / \mathrm{Pd}$ bimetallic alloys could be different from their thermodynamically most stable structure. Although $\mathrm{CO}$ molecules affect the $\mathrm{Pd}-\mathrm{Au}$ swapping barrier, we find that the vacancy critically accelerates the PdAu swapping (Table 1).

3-3. Multiadsorption of $\mathrm{CO}$ on $\mathrm{Pd}$ Atoms and Subsequent Pd Clustering. Goodman and co-workers reported that the $\mathrm{Au} / \mathrm{Pd}(100)$ surface alloy catalyzes $\mathrm{CO}$ oxidation as contiguous $\mathrm{Pd}$ atoms in the surface layer dissociates $\mathrm{O}_{2}$ molecules. ${ }^{14,15}$ As experimental evidence, they resolved PM-IRRAS data acquired at $100 \mathrm{~K}$ and reported IR peaks of the bridging CO species, $\mathrm{Pd}-\mathrm{CO}^{*}-\mathrm{Pd}$, at 1999, 1976, and $1908 \mathrm{~cm}^{-1}$. These peaks are located below $2000 \mathrm{~cm}^{-1}$, whereas the peak that corresponds to $\mathrm{Pd}-\mathrm{CO}^{*}$ lies at 2085 $\mathrm{cm}^{-1}$ (Figure 3a).

DFT-calculated IR frequencies of the $\mathrm{Pd}-\mathrm{CO} *-\mathrm{Pd}$ were found at 1910, 1904, and $1902 \mathrm{~cm}^{-1}$, which are in good agreement with the experimental value of $1908 \mathrm{~cm}^{-1}$ (Figure $3 \mathrm{~d}, \mathrm{e})$. We found that the experimental peak at $1999 \mathrm{~cm}^{-1}$ is coming from the harmonics between adjacent two $\mathrm{Pd}-\mathrm{CO}^{*}$ species (see Figure 3c). The experimentally reported IR peak at $1976 \mathrm{~cm}^{-1}$ is likely due to bridge CO molecules bound to Pd atom clusters. We found a frequency at $1930 \mathrm{~cm}^{-1}$ (Figure 3e) in a $\mathrm{Pd}_{6}$ cluster model. Additional subsurface $\mathrm{Pd}$ atoms would shift these values to higher energies. DFT-calculated IR frequencies of weakly bound $\mathrm{Pd}-\mathrm{CO} *-\mathrm{Au}$ species were found at 1893 and $1891 \mathrm{~cm}^{-1}$ (Figure 3b, d, and e). These 


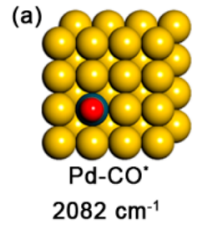

$\left(2085 \mathrm{~cm}^{-1}\right)$

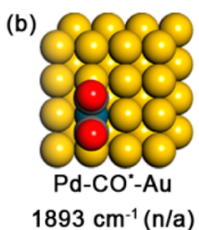

$1893 \mathrm{~cm}^{-1}$ (n/a)

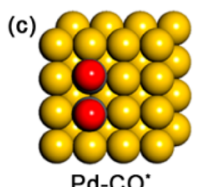

$2013 \mathrm{~cm}^{-1}, 1993 \mathrm{~cm}^{-1}$

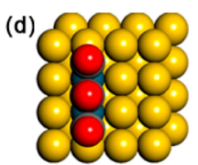

Pd-CO'-Pd,Pd-CO'-Au

$1910 \mathrm{~cm}^{-1}, 1893 \mathrm{~cm}^{-1}$

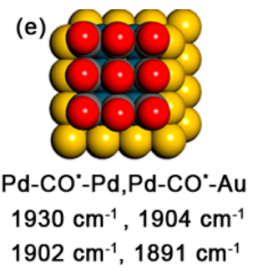

$\left(1999 \mathrm{~cm}^{-1}, 1976 \mathrm{~cm}^{-1}, 1908 \mathrm{~cm}^{-1}\right)$

Figure 3. DFT calculated IR frequencies of surface CO species: (a, b) Pd monomer, (c, d) Pd dimer, and (e) Pd cluster consisting of six Pd atoms. Values in parentheses show experimental IR data. ${ }^{14,15}$

modes, however, would disappear as the $\mathrm{Pd}-\mathrm{CO}^{*}$ and $\mathrm{Pd}-$ $\mathrm{CO}^{*}-\mathrm{Pd}$ become a dominant species, at increased $\mathrm{Pd}$ concentrations.

Given the well-known $\mathrm{CO}$ binding nature on CO-philic metal surfaces (single $\mathrm{CO}$ adsorption on a metal atom), $\mathrm{CO}$ stripping has been used to determine the surface coverage of CO-philic metal elements of bimetallic systems. ${ }^{25}$ Galhenage et al. found that the surface concentration of $\mathrm{Co}, \mathrm{Ni}$, or Pt of $\mathrm{Au}-$ based bimetallic clusters supported on $\mathrm{TiO}_{2}$ estimated by $\mathrm{CO}$ temperature-programmed desorption is greater than that from a low-energy ion scattering experiment. ${ }^{25}$ We postulate that the presence of the bridge-bound $\mathrm{CO}$ is attributed to the overestimated surface concentration of the CO-philic element estimated by $\mathrm{CO}$ temperature-programmed desorption.

Soto-Verdugo and Metiu showed that the repulsive force between adjacent $\mathrm{Pd}-\mathrm{CO}^{*}$ 's is low; Supporting Information Figure $\mathrm{S} 1$ confirms their finding. ${ }^{16}$ Because the binding energy of the bridging $\mathrm{CO}$ molecule $\left(\mathrm{Pd}-\mathrm{CO}^{*}-\mathrm{Pd}\right)$ is higher than the on-top $\mathrm{Pd}-\mathrm{CO}^{*}$ molecule, as $\mathrm{Pd}$ atoms segregate to the surface (see Figure 4), these bridge-bound CO molecules would promote Pd clustering.

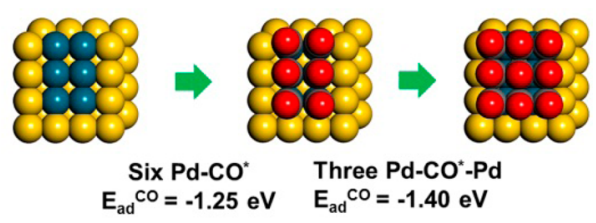

Figure 4. Strong binding of $\mathrm{Pd}-\mathrm{CO} *-\mathrm{Pd}$ on the $\mathrm{Pd}_{6}$ cluster. The stronger binding of the final three $\mathrm{CO}$ molecules supplies a driving force for Pd clustering.

3-4. CO Oxidation by Pd Motifs. To provide insight into the reactive species, we studied $\mathrm{CO}$ oxidation by several $\mathrm{CO}$ species at the surface of $\mathrm{Pd}-\mathrm{Au}(100)$ : (1) Pd monomer with a single on-top $\mathrm{CO}, \mathrm{Pd}-\mathrm{CO}^{*}$ (M1), (2) Pd monomer with two bridging CO's, $\mathrm{Pd}-\mathrm{CO}^{*}-\mathrm{Au}(\mathrm{M} 2)$, (3) Pd dimer with two on- top CO's, $\mathrm{Pd}-\mathrm{CO}^{*}$ (D1), and (4) Pd dimer with three bridging CO's, one bridging $\mathrm{Pd}-\mathrm{CO}^{*}-\mathrm{Pd}$, and two bridging $\mathrm{Pd}-\mathrm{CO}^{*}-\mathrm{Au}$ 's (D2). Refer to Figure 5 for the detailed geometry of these models. We found, however, that these species cannot bind $\mathrm{O}_{2}$ strongly enough to catalyze $\mathrm{CO}$ oxidation. Under $\mathrm{CO}$ oxidation conditions, $\mathrm{M} 1$ would prefer to bind an additional $\mathrm{CO}$ molecule $\left(E_{\mathrm{b}}=-0.96 \mathrm{eV}\right)$, forming the $\mathrm{M} 2$ structure rather than binding an $\mathrm{O}_{2}$ molecule with a lower $(-0.44 \mathrm{eV})$ binding energy. In the case of $\mathrm{M} 2$, the available $\mathrm{Pd}$ sites are already saturated by $\mathrm{CO}$ molecules so that coadsorption of $\mathrm{O}_{2}$ with the two $\mathrm{CO}$ molecules $(-0.27 \mathrm{eV})$ is weak. Note that the binding energy of $\mathrm{O}_{2}$ on $\mathrm{M} 2$ is lower than the entropic contributions to the free energy of $\mathrm{O}_{2}$ desorption, $-0.64 \mathrm{eV}$ (the entropic contribution to the Gibbs free energy of $\mathrm{O}_{2}$ desorption at the conventional operating temperature of $\mathrm{CO}$ oxidation is $-0.64 \mathrm{eV}$ at $298 \mathrm{~K}$ and $1 \mathrm{bar}$; the standard entropy of $\mathrm{O}_{2}$ at $298 \mathrm{~K}^{\text {is }} 205.14 \mathrm{~J} \mathrm{~mol}^{-1} \mathrm{~K}^{-1}$ ), ${ }^{26,27}$ confirming that additional binding of $\mathrm{O}_{2}$ on $\mathrm{M} 2$ is not favorable (see the Supporting Information for details). D1 would prefer to bind additional $\mathrm{CO}\left(E_{\mathrm{b}}=-1.21 \mathrm{eV}\right)$ rather than $\mathrm{O}_{2}\left(E_{\mathrm{b}}=\right.$ $-0.69 \mathrm{eV})$. Weak $\mathrm{O}_{2}$ binding at $\mathrm{D} 2\left(E_{\mathrm{b}}=-0.22 \mathrm{eV}\right)$ also shows that $\mathrm{D} 2$ is not a good catalyst geometry for $\mathrm{CO}$ oxidation. $\mathrm{CO}$ oxidation by a catalyst that weakly binds $\mathrm{O}_{2}$ and cannot supply a reactive $\mathrm{O}^{*}$ species usually follows the Langmuir-Hinshelwood mechanism, requiring the association of coadsorbed $\mathrm{CO}^{*}$ and $\mathrm{O}_{2} *{ }^{9,10,28-30}$ Results show that isolated $\mathrm{Pd}$ atoms or dimers cannot activate $\mathrm{CO}$ oxidation by the association of coadsorbed $\mathrm{CO}^{*}$ and $\mathrm{O}_{2} *$.

Table 2 shows that the binding preference of the Pd cluster changes from $\mathrm{CO}$ to $\mathrm{O}_{2}$ as the Pd cluster is composed of more than four $\mathrm{Pd}$ atoms; $\mathrm{Pd}_{4}$ and $\mathrm{Pd}_{6}$ clusters strongly bind $\mathrm{O}_{2}$. Because DFT calculations at the GGA level of theory have systematic errors in the binding energy of $\mathrm{O}_{2}$ and $\mathrm{CO}$, the relative binding energies (for example, $\Delta E_{\text {ad }}$ in Table 2) are expected to be more accurate than the absolute values. The qualitative trend in the value of $\Delta E_{\mathrm{ad}}$, changing from positive to negative at $\mathrm{Pd}_{4}$, leads us to conclude that the binding of $\mathrm{O}_{2}$ is favored over $\mathrm{CO}$ in $\mathrm{Pd}$ clusters larger than $\mathrm{Pd}_{4}$. Moreover,
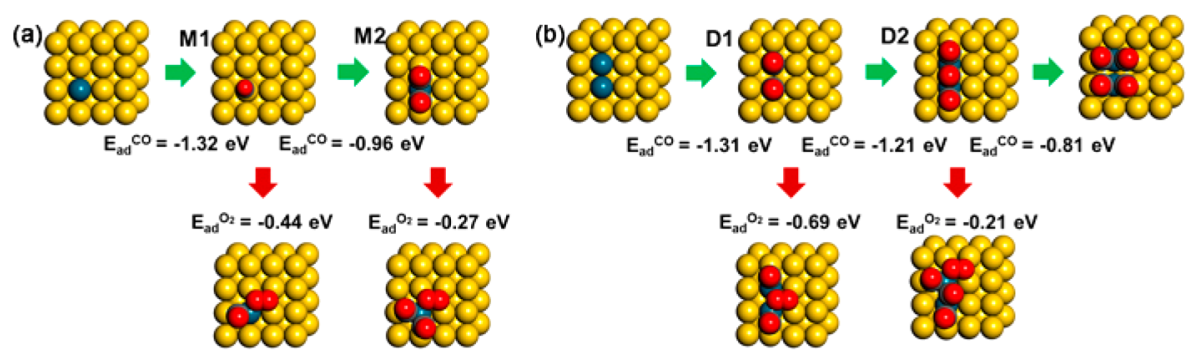

Figure 5. Trends in competitive $\mathrm{CO}$ and $\mathrm{O}_{2}$ binding on the $\mathrm{Pd}$ monomer (a) and $\mathrm{Pd}$ dimer $(\mathrm{b})$ in the $\mathrm{Pd}-\mathrm{Au}(100)$ surface. $\mathrm{Pd}$ monomer and dimer prefer to bind $\mathrm{CO}$ molecules as much as possible (green arrows) rather than binding an $\mathrm{O}_{2}$ molecule with CO molecules (red arrows). The associative mechanism of $\mathrm{CO}$ oxidation, ${ }^{9,10,28} \mathrm{CO}$ oxidation by coadsorbed $\mathrm{O}_{2}$ and $\mathrm{CO}$ is not the case of the Pd monomer and dimer. 
Table 2. Trends in $\mathrm{CO}$ Adsorption and $\mathrm{O}_{2}$ Adsorption and Dissociation on $\operatorname{Pd}_{x}$ Clusters ${ }^{a}$

\begin{tabular}{lrrrr} 
& \multicolumn{1}{c}{$\mathrm{Pd}_{1}$} & \multicolumn{1}{c}{$\mathrm{Pd}_{2}$} & \multicolumn{1}{c}{$\mathrm{Pd}_{4}$} & \multicolumn{1}{c}{$\mathrm{Pd}_{6}$} \\
$E_{\mathrm{ad}}^{\mathrm{CO}}(\mathrm{eV})$ & -1.14 & -1.17 & -1.28 & -1.30 \\
$E_{\mathrm{ad}}^{\mathrm{O}_{2}}(\mathrm{eV})$ & -0.77 & -1.06 & -1.57 & -1.66 \\
$\Delta E_{\mathrm{ad}}=E_{\mathrm{ad}}^{\mathrm{O}_{2}}-E_{\mathrm{ad}}^{\mathrm{CO}}$ & 0.37 & 0.09 & -0.29 & -0.36 \\
$\mathrm{O}_{2}$ dissociation energy $(\mathrm{eV})$ & $\mathrm{n} / \mathrm{a}$ & $\mathrm{n} / \mathrm{a}$ & 0.04 & -0.86 \\
$E_{\mathrm{b}}(\mathrm{eV})$ & $\mathrm{n} / \mathrm{a}$ & $\mathrm{n} / \mathrm{a}$ & 0.28 & 0.16
\end{tabular}

${ }^{a} E_{\mathrm{ad}}^{\mathrm{CO}}, E_{\mathrm{ad}}^{\mathrm{O}_{2}}$, and $E_{\mathrm{b}}$ denotes average energy of $\mathrm{CO}$ adsorption, energy of $\mathrm{O}_{2}$ adsorption, and $\mathrm{O}_{2}$ dissociation barrier, respectively. $\mathrm{Pd}_{x}$ is a $\mathrm{Pd}$ cluster composed of $x \mathrm{Pd}$ atoms on the $\mathrm{Pd}-\mathrm{Au}(100)$ surface. $E_{\mathrm{ad}}^{\mathrm{CO}}$ was calculated with two, four, six, and nine bound $\mathrm{CO}$ molecules to $\mathrm{Pd}_{1}$, $\mathrm{Pd}_{2}, \mathrm{Pd}_{4}$, and $\mathrm{Pd}_{6}$, respectively.

clustering of $\mathrm{Pd}$ atoms lowers the activation energy of $\mathrm{O}_{2}$ dissociation, leading to easier $\mathrm{O}_{2}$ dissociation and promoting subsequent $\mathrm{CO}$ oxidation by highly reactive $\mathrm{O}^{*}$ that oxidizes $\mathrm{CO}$ by the Langmuir-Hinshelwood mechanism or the EleyRideal mechanism (refer to Supporting Information Figure S2 for detailed geometries of $\mathrm{O}_{2}$ adsorption and dissociation of $\mathrm{Pd}_{4}$ and $\left.\mathrm{Pd}_{6}\right) \cdot{ }^{9,10}$ We postulate that although some $\mathrm{CO}$ molecules on the Pd atoms of Pd clusters that drive Pd surface segregation would be removed from the surface as a result of $\mathrm{CO}$ oxidation, $\mathrm{Pd}$ clusters would stay in the surface layer under $\mathrm{CO}$ oxidation condition as a result of strong $\mathrm{O}_{2}$ binding to the Pd clusters. Because the $\mathrm{CO}$ oxidation in this system is catalyzed by $\mathrm{Pd}$ motifs larger than $\mathrm{Pd}_{4}$, the overall $\mathrm{CO}$ oxidation reactivity would converge to those of the pure Pd (100) surface.

Given the stronger $\mathrm{CO}$ binding energy of Pd motifs smaller than $\mathrm{Pd}_{4}$ (see Table 2), CO binding on a $\mathrm{Pd}$ atom initially supplies a driving force for Pd surface segregation. As the size of Pd motifs increase larger than $\mathrm{Pd}_{4}$, the strong oxygen binding on $\mathrm{Pd}$ motifs larger than $\mathrm{Pd}_{4}$ would attribute to further $\mathrm{Pd}$ surface segregation, as well.

Because the $\mathrm{Au}-\mathrm{Pd}$ catalyst is exposed to $\mathrm{CO}$ oxidation conditions (a mixture of $\mathrm{CO}$ and $\mathrm{O}_{2}$ ), the reduction of the $\mathrm{Pd}-$ $\mathrm{O}^{*}$ by $\mathrm{CO}$ would be very fast (by the Eley-Rideal mechanism). The PdO oxide islands, therefore, would not be stabilized (the life span of the oxide at the surface layer of Pd$\mathrm{Au}$ alloy would be short). Even though ideal theoretical calculations could predict the formation of $\mathrm{PdO}$ islands in oxygen-rich conditions, it would not be the case of the real $\mathrm{CO}$ oxidation conditions.

\section{SUMMARY}

According to conventional computational catalyst design methods, which have focused on ensemble and ligand effects, a low concentration of $\mathrm{Pd}$ in a $\mathrm{Au}$ alloy would not likely be regarded as a catalyst for $\mathrm{CO}$ oxidation because $\mathrm{Au}$ surface atoms cannot bind and dissociate $\mathrm{O}_{2}$. Herein, we suggest, however, that under $\mathrm{CO}$ oxidation conditions where the $\mathrm{CO}$ induced $\mathrm{Pd}$ surface segregation occurs, the $\mathrm{Pd}-\mathrm{Au}(100)$ bimetallic alloy becomes an effective $\mathrm{CO}$ oxidation catalyst. The strong CO-philic nature of Pd supplies a driving force for preferential surface segregation of Pd atoms, and a Au vacancy dramatically accelerates the $\mathrm{Pd}-\mathrm{Au}$ swapping. This finding predicts that an adsorption-induced surface segregation would be more prominent in nanoparticles or rough surfaces, where surface atoms are less closely packed.

$\mathrm{Pd}$ clusters composed of at least four Pd atoms are found to be a reactive species for $\mathrm{CO}$ oxidation. Facile $\mathrm{O}_{2}$ dissociation by $\mathrm{Pd}$ clusters is essential for high $\mathrm{CO}$ oxidation activity. Our findings suggest that not only are geometric and electronic effects important, but dynamical effects also have to be considered for bimetallic alloys or NPs whose components asymmetrically interact with reacting molecules.

\section{ASSOCIATED CONTENT}

\section{S Supporting Information}

Details about the DFT calculations of the free energy of $\mathrm{O}_{2}$ binding and $\mathrm{CO}$ repulsion are provided. This material is available free of charge via the Internet at http://pubs.acs.org.

\section{AUTHOR INFORMATION}

\section{Corresponding Author}

*E-mail: hykim8083@gmail.com, henkelman@cm.utexas.edu.

\section{Present Address}

${ }^{\dagger}$ Center for Functional Nanomaterials, Brookhaven National Laboratory, Upton, New York, 11973

Notes

The authors declare no competing financial interest.

\section{ACKNOWLEDGMENTS}

We gratefully acknowledge support from the Chemical Sciences, Geosciences, and Biosciences Division, Office of Basic Energy Sciences, Office of Science, U.S. Department of Energy (Contract: DE-FG02-13ER16428). Computing time was provided by the National Energy Research Scientific Computing Center and the Texas Advanced Computing Center at the University of Texas at Austin.

\section{REFERENCES}

(1) Crooks, R. M.; Ye, H. C. J. Am. Chem. Soc. 2007, 129, 36273633.

(2) Greeley, J.; Mavrikakis, M. Nat. Mater. 2004, 3, 810-815.

(3) Hammer, B.; Norskov, J. K. Adv. Catal. 2000, 45, 71-129.

(4) Gross, A. Top. Catal. 2006, 37, 29-39.

(5) Norskov, J. K.; Bligaard, T.; Rossmeisl, J.; Christensen, C. H. Nat. Chem. 2009, 1, 37-46.

(6) Greeley, J.; Stephens, I. E. L.; Bondarenko, A. S.; Johansson, T. P.; Hansen, H. A.; Jaramillo, T. F.; Rossmeisl, J.; Chorkendorff, I.; Norskov, J. K. Nat. Chem. 2009, 1, 552-556.

(7) Honkala, K.; Hellman, A.; Remediakis, I. N.; Logadottir, A.; Carlsson, A.; Dahl, S.; Christensen, C. H.; Norskov, J. K. Science 2005, $307,555-558$.

(8) Studt, F.; Abild-Pedersen, F.; Bligaard, T.; Sorensen, R. Z.; Christensen, C. H.; Norskov, J. K. Science 2008, 320, 1320-1322.

(9) Kim, H. Y.; Han, S. S.; Ryu, J. H.; Lee, H. M. J. Phys. Chem. C 2010, 114, 3156-3160.

(10) Kim, H. Y.; Kim, D. H.; Ryu, J. H.; Lee, H. M. J. Phys. Chem. C 2009, 113, 15559-15564.

(11) Tao, F.; Grass, M. E.; Zhang, Y. W.; Butcher, D. R.; Renzas, J. R.; Liu, Z.; Chung, J. Y.; Mun, B. S.; Salmeron, M.; Somorjai, G. A. Science 2008, 322, 932-934.

(12) Tao, F.; Grass, M. E.; Zhang, Y. W.; Butcher, D. R.; Aksoy, F.; Aloni, S.; Altoe, V.; Alayoglu, S.; Renzas, J. R.; Tsung, C. K.; Zhu, Z. W.; Liu, Z.; Salmeron, M.; Somorjai, G. A. J. Am. Chem. Soc. 2010, 132, 8697-8703.

(13) Tenney, S. A.; Ratliff, J. S.; Roberts, C. C.; He, W.; Ammal, S. C.; Heyden, A.; Chen, D. A. J. Phys. Chem. C 2010, 114, 2165221663.

(14) Gao, F.; Wang, Y. L.; Goodman, D. W. J. Phys. Chem. C 2009, 113, 14993-15000.

(15) Gao, F.; Wang, Y. L.; Goodman, D. W. J. Am. Chem. Soc. 2009, 131, 5734-5735.

(16) Soto-Verdugo, V.; Metiu, H. Surf. Sci. 2007, 601, 5332-5339.

(17) Kresse, G.; Furthmuller, J. Comput. Mater. Sci. 1996, 6, 15-50. 
(18) Perdew, J. P.; Burke, K.; Ernzerhof, M. Phys. Rev. Lett. 1996, 77, 3865-3868.

(19) Blochl, P. E. Phys. Rev. B 1994, 50, 17953.

(20) Henkelman, G.; Jonsson, H. J. Chem. Phys. 2000, 113, 99789985.

(21) Henkelman, G.; Uberuaga, B. P.; Jonsson, H. J. Chem. Phys. 2000, 113, 9901-9904.

(22) Ruban, A. V.; Skriver, H. L.; Norskov, J. K. Phys. Rev. B 1999, 59, 15990-16000.

(23) Mejia-Rosales, S. J.; Fernandez-Navarro, C.; Perez-Tijerina, E.; Blom, D. A.; Allard, L. F.; Jose-Yacaman, M. J. Phys. Chem. C 2007, $111,1256-1260$.

(24) Xu, J.; White, T.; Li, P.; He, C. H.; Yu, J. G.; Yuan, W. K.; Han, Y. F. J. Am. Chem. Soc. 2010, 132, 10398-10406.

(25) Galhenage, R. P.; Ammal, S. C.; Yan, H.; Duke, A. S.; Tenney, S. A.; Heyden, A. J. Phys. Chem. C 2012, 116, 24616-24629.

(26) Atkins, P.; Paula, J. D. Physical Chemistry, 8th ed.; Oxford: New York, 2006.

(27) Metiu, H. Physical Chemistry: Statistical Mechanics, 1st ed.; Taylor \& Francis: New York, 2006.

(28) Liu, Z.-P.; Hu, P.; Alavi, A. J. Am. Chem. Soc. 2002, 124, 1477014779.

(29) Falsig, H.; Hvolbaek, B.; Kristensen, I. S.; Jiang, T.; Bligaard, T.; Christensen, C. H.; Norskov, J. K. Angew. Chem., Int. Ed. 2008, 47, 4835-4839.

(30) Kim, H. Y.; Lee, H. M.; Henkelman, G. J. Am. Chem. Soc. 2012, $134,1560-1570$. 